\title{
Tales of IT Consultants: Understanding Psychological Contract Maintenance and Employment Termination
}

\author{
Karlheinz Kautz \\ Faculty of Business \\ University of Wollongong \\ kautz@uow.edu.au \\ Gro Bjerknes \\ Information Technology Services \\ University of Wollongong \\ gro.bjerknes@gmail.com
}

\section{Abstract}

This research investigates the question why dedicated Information Technology (IT) consultants quit their jobs and voluntarily terminate their employment contracts. A research approach inspired by grounded theory is used and as a theoretical contribution a novel, cyclic process model for the maintenance or neglect of the psychological contract between employees and employers is derived from the empirical data. The model is subsequently substantiated through the integration of various concepts and theories identified in theliterature, combining the concept of psychological contract with social influence theory and a theory of the relation between intrinsic motivation and management practices. The research is based on a revelatory case study which provides tales from four IT consultants in an IT consulting firm. The model helps to explain IT consultants' behaviour of voluntarily terminating their employment contracts. Additionally, it should assist managers in IT consulting firms to avoid practices which might lead to their employees' loss of intrinsic motivation and result in the loss of valuable employees for the organization.

Keywords: Psychological contract; voluntary contract termination; IT Consultants

\section{Introduction}

Why do dedicated IT consultants quit their job and leave their employing IT consulting firm during a current labour market climate with job shortages, downsizing and salary cuts, where they are among the privileged who could keep their jobs during several rounds of farewell packages and layoffs? This was the starting point for the work presented in this paper. It reports the results of research which answers this question by providing the tales and stories of four IT consultants who worked in the same (Scandinavian) IT consulting firm - in the following referred to as the Company due to a confidentiality agreement. The second author of this article and primary empirical investigator of the work described here was for many years employed in the Company confronted with this phenomenon.

Using an innovative and rigorous research approach inspired by grounded theory we develop a model of the process which leads to the IT consultants' voluntary employment termination and subsequently substantiate the model through the integration of various concepts and theories identified in the literature. We draw on the concept of psychological contract (Rousseau 1995, Morrison and Robinson 1997, Carr 2001, Guest 2004), integrating it with social influence theory (Cialdini 2001a, b) and a theory of the relation between intrinsic motivation and management practices (Amabile 1998) into a cyclic model of 'the maintenance or neglect of the psychological contract' between employees and their employing organization. Through the analysis of the four stories we derive theoretical and practical insights about the phenomenon under investigation, both with regard to the voluntary termination of employment contracts during a crisis situation within the IT industry, and also in a wider context. 
The concept of psychological contract describes the informal aspects of an employment relationship (Svedberg 2000, Carr 2001). The first appearance of the concept is commonly attributed to Argyris (1960) who called the relationship between employees and their foremen a 'psychological work contract.' Schein (1970) used the concept to discuss the informal relationship between consultants and clients. In Information Systems (IS) research Sabherwal (1999) used the concept in this context and analysed the informal relationship between a customer organization and an IT supplier in a case study where the supplier developed a computerized information system based on customer-defined specifications. Employment is a long term relationship that is governed by a formal contract. However, according to transaction cost theory resources are required to maintain long-term contracts and in this context, informal, relational contracts are often established in addition to the formal ones to reduce the possibility of opportunism (Barney 1996). A psychological contract helps to regulate informal work situations and the expectations between the involved parties and what they provide to each other (Svedberg 2000). In addition to salary employees want to derive meaning and satisfaction from work (Morse 2003), and in this regard a psychological contract plays a significant role as well. Psychological contracts are however obscure, they often only exist unconsciously (Carr 2001). As its content is vague, an important aspect of a psychological contract is that the expectations in relation to the contract are met.

The remainder of the paper is structured as follows. In the two following sections we introduce our research approach and present the stories of the four IT consultants. We then describe the theoretical consideration and the resulting model in more detail. Subsequently, we revisit and analyse these stories in light of the theoretical model and discuss our results together with our theoretical and practical insights and the limitations of our work. Finally we summarize our contributions and provide avenues for further research.

\section{Research Approach and Method}

Given the background of the second author the purpose of the study was to investigate in an unbiased manner why dedicated IT consultants quit their job; the purpose was not to examine whether the consultants behaved in a specific preconceived and hypothesised way. The study was thus explorative and qualitative in nature and based on open-ended interviews (Creswell 2003). Its emergent strategy with no specific hypothesis suggested the adoption of a method that allowed for whichever explanatory variables and concepts. Without hypotheses to be verified or invalidated, the data collection had to be more open than a search for the impact of already known factors. We therefore opted for a case study or, more precisely case studies based on storytelling with the stories documented in the form of narratives (Gabriel 2000) and an analysis using an approach inspired by grounded theory (Glaser and Strauss 1967, Strauss and Corbin 1998, Locke2001). Storytelling in combination with narratives is acknowledged as a valuable research approach in IS (Kendall and Kendall 2012).

Letting respondents speak for themselves and give their own explanations through the provided data reveals the immediate reasons and reasoning behind conclusions and adds a more direct and valid touch to the results. In line with some of our earlier work (Hansen and Kautz 2005, Kjærgaard and Kautz 2008) we deduced relevant issues directly from the data and examined these issues and their interrelationships more closely, avoiding unnecessary interpretation of the interviewees' statements where possible. In other words, the results informing the cyclic process model were 'grounded' directly in the observed data instead of being produced e.g. by deduction or other 'intellectual experiments' (Hansen and Kautz 2005).

In spite of our open and emergent strategy and Glaser's (1992) advice that there is no need to review any literature in the area under study so as not to 'contaminate' the researchers' interpretation of data, we followed Walsham's (1995) warning against ignoring existing theory completely and Strauss and Corbin's (1998) suggestion to build up a certain theoretical sensitivity. Thus, we subsequently allowed the literature to inform us about the subject, which is in line with interpretive case studies (Walsham 1995) and we have been inspired by existing literature within the area benefiting from previous results achieved by others. 
However as stated above the aim of the study was to solicit and understand the interviewees' own explanations; we thus did not explore and consider any other influences and drivers not stated by the consultants during the interviews for their employment and its subsequent termination. The primary reason for going back to existing literature was the extent of our study with its challenge of gathering sufficient data to examine all relevant aspects of the subject. We wished to achieve an interaction between the existing literature and our observations from the case organization to explain interrelationships and contribute to theory with new insight from practice. Although the purpose of the study was not to verify or refine existing theory we in particular used the literature to substantiate the derived process model and to apply it to understand and theorize about our findings from practice as well as to generalise this understanding into an explanatory model that might be useful for scholars and practitioners.

The ontological and epistemological assumptions of the study are informed by the interpretive paradigm, and accordingly the role of those involved in the investigated phenomenon is understood as that of active constructors of meaning as well as active interpreters of reality. Their meaning construction process is central and forms the basis for understanding their actions. Our study took place in a single case organization and we selected a revelatory case, or rather cases, if we consider the individual informants (Yin 2009), which has not been described in the IS literature before. Such cases are considered to be prototypical or paradigmatic of the phenomenon of interest (Gerring 2007) and by studying the case organization and the informants we were able to illuminate key aspects of the process, which led to IT consultants' voluntary employment termination, and to develop a model of what we term a cyclic process of the maintenance or neglect of the psychological contract. In contrast to a representative case selection our objective is to introduce ideal types, which are formed by the one-sided accentuation of one or more points of view (Weber 1949). As such, theidentified constructs and the subsequently presented model exhibit in their current form an instance of theorizing through idealization (Lopreato and Alston 1970, Ghazawneh and Henfridsson 2013), which needs to be further validated. This approach might be criticised for initially only generating a local empirical theory which might not be generalisable, but as argued by Hughes and J ones (2003) it contributes to the existing body of knowledge by providing a detailed account of empirical findings.

There are two reasons why the Company is suitable for this endeavour. First, the Company's history (see next section) involves a number of alterations in its strategy, which allowed us to segregate specific episodes for tracing underlying patterns and enabled temporal decomposition, which is important in process studies (Langley 1999, Ghazawneh and Henfridsson 2013). Second, as an employee of the Company herself and a long-time colleague of the study participants, the second author who performed the data collection had the role of an insider researcher and shared an identity, language, and experiential base with them (Asselin 2003). Being an insider researcher enhances the depth and breadth of understanding a population that may not be accessible to a non-native researcher, but it also raises questions about objectivity, reflexivity, and the authenticity of the research project, because the insider might know too much or is too close to the project and may be too similar to those being studied (Kanuha 2000).

The study is based on in-depth interviews with four consultants, who had finished in the Company. They were selected because they all had a high regard among their colleagues in the Company and they all continued to perform the same kind of jobs and assignments in their new careers; job content as such had not been a reason for their employment and employment termination. They also had in common that they (a) ceased their employment by their own choice, they did not receive a farewell package or were laid-off; (b) had been employed for a long time, at least seven years; (c) they had been active in the professional development in their areas of expertise and demonstrated their commitment by giving more to the Company than they were obliged to. Each consultant was interviewed intensively once with each interview lasting about two hours. 
The interviews were based on a vitagram, i.e. a graph, which the interviewees produced before their interview showing their employment and working life satisfaction in the Company over time. Vitagrams have been used in medicine to capture quality of life since the 1970s (see Armstrong et al. 2007). To support the interviewees during the report of their stories we used an interview guide and open questions, which took their starting point in the vitagram. Once triggered by an overall question vitagrams are very useful because they let the interviewees tell their own story and develop their own narrative independent of the interviewer's preconception or any questions developed on a specific theoretical foundation. In that sense the chosen research approach was similar to a grounded theory approach and supported the uncontaminated collection and initial analysis of the empirical data. During and immediately after the interviews interview reports were produced which the interviewees read, commented upon and approved, which built the background for the subsequent analysis. In line with the story telling approach and with the research question as the point of departure the data was openly coded and thematically analysed for similarities and patterns, as well as for disparities and idiosyncrasies and for notable episodes and incidents, but no extensive axial and selective coding was performed.

To meet the mentioned challenges, especially to avoid an insider's bias and to avoid influencing the respondents two further countermeasures were taken: to be very conscious about them, the inside researcher wrote down her own expectations of what she would find through the investigation before she started the interviews and very open questions not based on any of these assumptions, but rather on each individual's vitagram, were chosen. Still, we found that the respondents took some truths for granted - they did not elaborate on them, as they assumed the interviewer to know these based on their shared history. In spite of that, the differences between the stories that were told, were much larger than expected and they were different from the story the inside researcher had written down herself. The same is valid with regard to the consultants' motives to quit their jobs. None of the expected references to the general crisis in the IT industry, the company's changing environment through mergers and acquisitions, de-mergers and separations with the resulting exposure to new managers were mentioned as influences for their employment termination and were for that reason not considered in the further analysis. Hence, although the inside researcher might have influenced some details of the interviews by pointing to examples and incidents, we can conclude that this has had little or no bearing on the major features of the stories, and therefore it has been justifiable to use the collected empirical data to develop the model.

\section{The Tales of the IT Consultants}

The Company, which builds the background for the four tales of the interviewed consultants, is a management and IT consulting firm. It works with innovative restructuring processes in which IT is a key instrument for achieving business goals and for helping its customers to add value. For anonymity purposes we named the four consultants Art, Bee, Curt and Di. The Company was founded in the late 1980s by about 40 IT consultants, who had left another organization. After initial problems, during the next 12 years the Company went very well and grew steadily through mergers and acquisitions to about 1200 employees, among others through a major merger with another larger and more technology-oriented firm. It was also listed on the stock exchange. To stimulate the employees, incentive programmes including stock options and immediate cash rewards were established. However, in line with other IT consultancies the Company had grown too fast and too large and when an economic crisis hit the IT sector around the year 2000, too many companies competed on a small market with too few customers. Thus in the following three years parts of the Company were sold again and in several rounds more than 100 employees accepted farewell packages while approximately another 50 were laid off and the salary system was changed into a variable pay scheme. At the end of the period, which also demarcates the end of this research, the Company had shrunk to 600 employees again.

Each consultant's story includes their vitagram (Figures 1 - 4) which was produced as part of the interview. The vertical line on the vitagram marks a common point in time, and from this 
point the stories take place in the same time period. Each story focuses on what is special for each consultant. Common features of the stories, i.e. things that are mentioned by two or more consultants, are collected at the end of this section in a separate subsection.

\subsection{Art's Story}

When Art started, he was very pleased with the organization. A good social environment prevailed and he soon got assignments to work for customers. Although he at one point withdrew a little from the general social life in the organization, he still participated in the Company's internal life as an active member of one of the Company's professional core experience groups.

Satisfaction

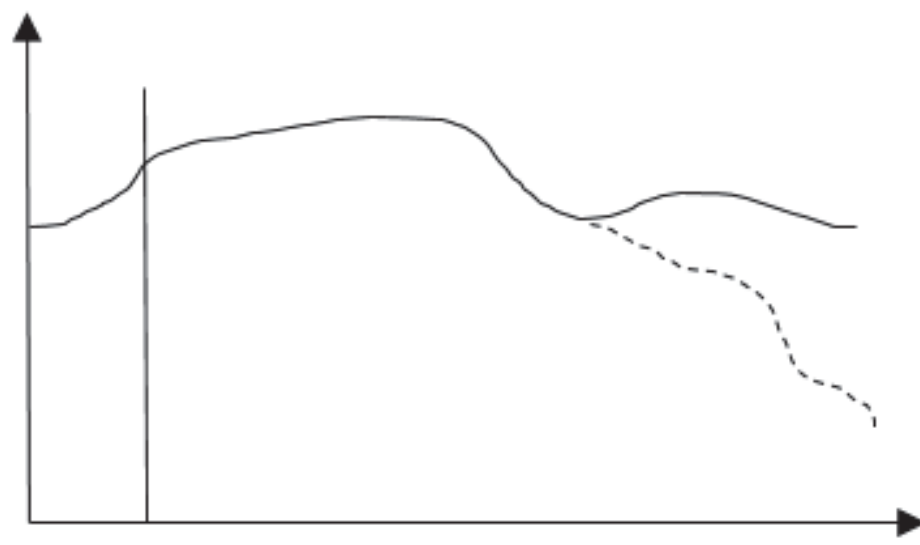

Time

Figure 1: Art's Vitagram

The first time he became unhappy and felt let down was when he was assigned to a project with another consultant, who was not competent to perform the task. Art informed his manager about this, but nothing happened. He had expected to either get an additional competent person or a competent replacement for the one who was on the project, so that the Company would have a real chance to deliver a good result. This did not happen, but Art considered it a one-off event. But when Art was assigned to the next project and the same happened again, his motivation decreased dramatically which he expressed through the dashed line in his vitagram. Nevertheless, Art was still content, but that was mostly because the project gave him an opportunity for personal growth and that was satisfactory. His commitment to the project was strong, but the commitment to the Company became less and less. The final 'blow' which led to Art's decision to resign was one of the last lay-off rounds. Art experienced the lay-offs as deeply unfair and felt that they struck blindly. When asked about the organizational culture, Art replied that the Company had no clear understanding anymore of what the business should be and what the organization should specialize in. In his view this made it difficult to make personal choices that would increase the likelihood that one would keep one's job in times of cutbacks and layoffs.

\subsection{Bee's Story}

Bee started as a very satisfied employee. The first major downturn came about 1990, when the original Company had two rounds of layoffs before it was itself acquired by another organization - the vitagram shows this as the first trough. Bee felt that it was very hard to stay behind when her social network disintegrated and good colleagues disappeared. The reason why she did not leave herself at the time was that there was much uncertainty in her private life that it would have been too unsafe to switch jobs at the same time. The situation improved again and she was happy and thought there was a good balance between a focus on earnings, short-term gains and competence development, the opportunity for long term gains. Eventually, however the weight tipped over and there was less focus on competence 
development and she grew more and more frustrated as there was no longer a correlation between the tasks she was assigned to and the time she had available and she felt quite alone. So she handed in her notice - the second, slightly smaller trough in her vitagram - but when the organization decided to focus on something she was interested in, she changed her decision and stayed. Her joy however proved short-lived. The new unit she had joined consisted of people from many of the newly merged entities and it turned out that there was no real consensus on what the unit would work with. As the unit did not produce financial results fast enough, it was closed down. The Company's management after all did not wish to focus on this area. At this point her motivation decreased rapidly (the last great wave valley in the vitagram). Bee's personnel manager recognized this and got her quickly out in a project with a customer believing that her discontent would go over. But it did not.

Satisfaction

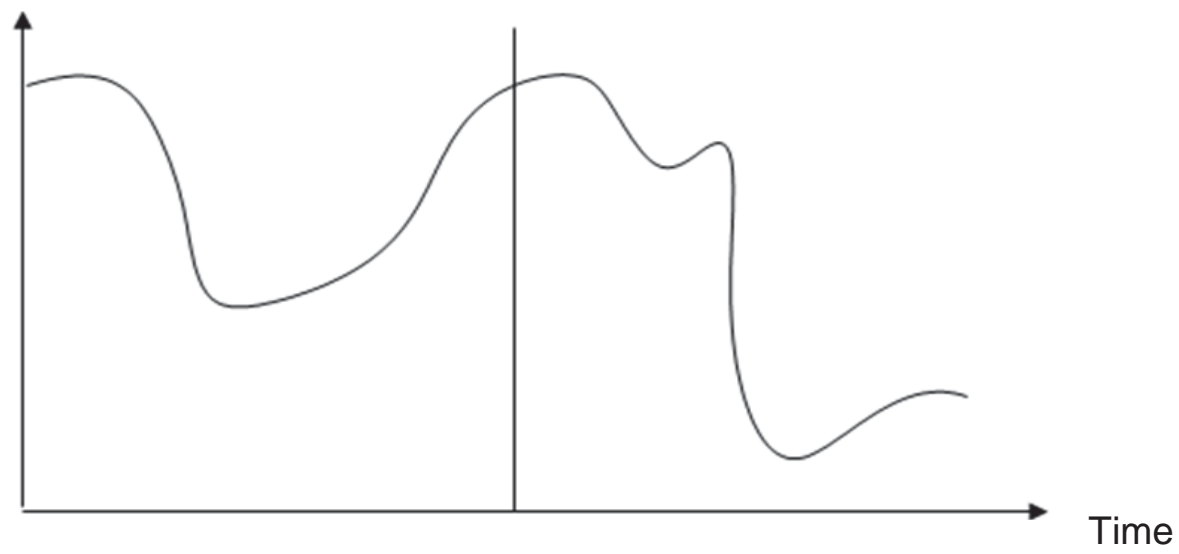

Figure 2: Bee's Vitagram

She felt obligated to the project, but when the time came to finalize the project, she had thought of looking for a new job. This decision was further strengthened by the last rounds of lay-offs. When management decided to use such means, which she disagreed with very much, she lost faith in management. Therefore it was not hard to say "yes" when a new job offer came. Bee described the changes in the organizational culture as a process, in which different values influenced the culture. At the start of the Company the focus was on creativity, cohesion and well-being. Then after the acquisition the first slump came with an engineering culture and focus on rationality and numbers. Then came a period of growth and focus on the stock exchange float - the solid vertical line in the vitagram represents this period, followed by a period of balance between short and long term gains and goals, and finally a period, where management had not been willing to pay 'the price for the growth of the company' by supporting its employees. 


\subsection{Curt's Story}

Satisfaction

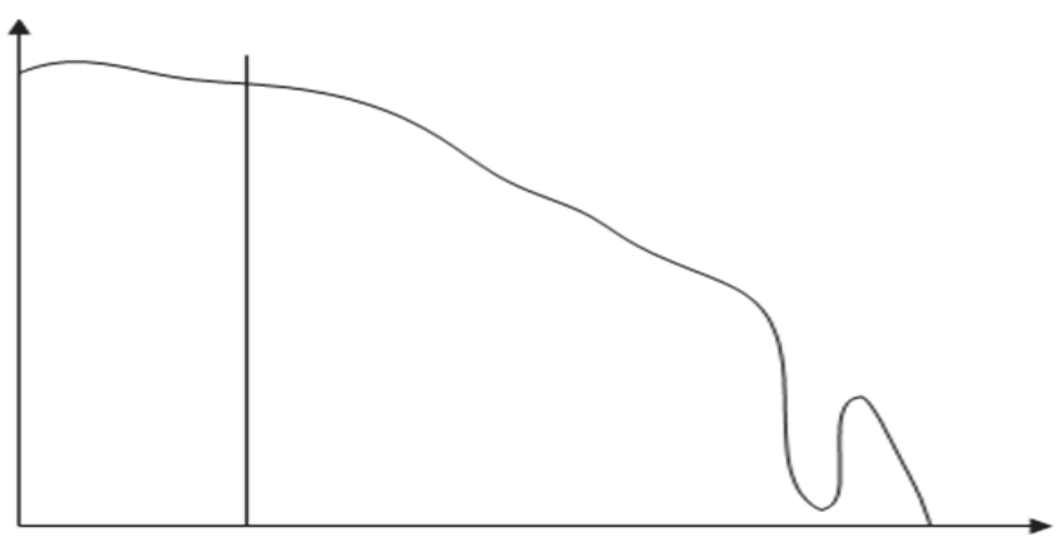

Time

Figure 3: Curt's Vitagram

Curt was also very happy at the start of his employment, but gradually his well-being deteriorated. He defined well-being as related to enthusiasm, commitment, motivation, and loyalty, which he believed had to be in place to be able to do a good job, and which has to be shared by co-workers and staff for an organization to be a good place to work. There were incidents that affected his well-being, such as when promises were not kept; for exampleit was said that professional development would count positively for salary and bonus determination, but it did not. There were also disappointments with regard to his expectations of management: he perceived leadership as clumsy, lacking reasonable thought and sometimes being unethical. As the organization's growth increased, simultaneously the workforce's general discontent rose and this also affected his well-being. When the redundancy packages were initiated, in addition to the layoffs and the introduction of variable pay, i.e. a $15 \%$ decline in salary, Curt thought that the job situation and his fixed income became too uncertain (first trough in the vitagram). However, when management withdrew the proposal for the variable pay model, he felt that his income was safe enough and determined to stay (next peak in the vitagram). But when the variable pay model was introduced again, he decided to leave and found himself a new job. Curt thought that the Company changed from being an organization with great openness, co-determination, and participation, where individual differences were seen as strength, and governance was executed according to individual needs, to an organization, which was completely closed, without co-determination and participation, where individual needs were ignored, and where governance was entirely executed according to economic principles. Those who managed and rewarded only saw numbers, not people.

\subsection{Di's Story}

Di started as a consultant, but eventually became a manager. She was mostly content, right up to the point where a reorganization of the Company in terms of market areas meant that she got a new superior. There her motivation and enthusiasm sank dramatically (the steep downward curve in her vitagram) as her new boss was not a collaborator; he merely gave orders. At the time Di was head of a department with 70 - 80 employees and she had three submanagers who reported to her and she divided the direct responsibility for the staff between them. Cooperation was important for her and she felt that the collaboration between her and the three managers in the department worked very well. She also thought it was part of her job to work together with other managers, both the top management team, and managers across the individual units, who took care of the different subjects and market segments to further develop and prepare the Company for the future. But she was not allowed to do so. As a consequence she felt overlooked by the management team and felt that the group did not work well. 


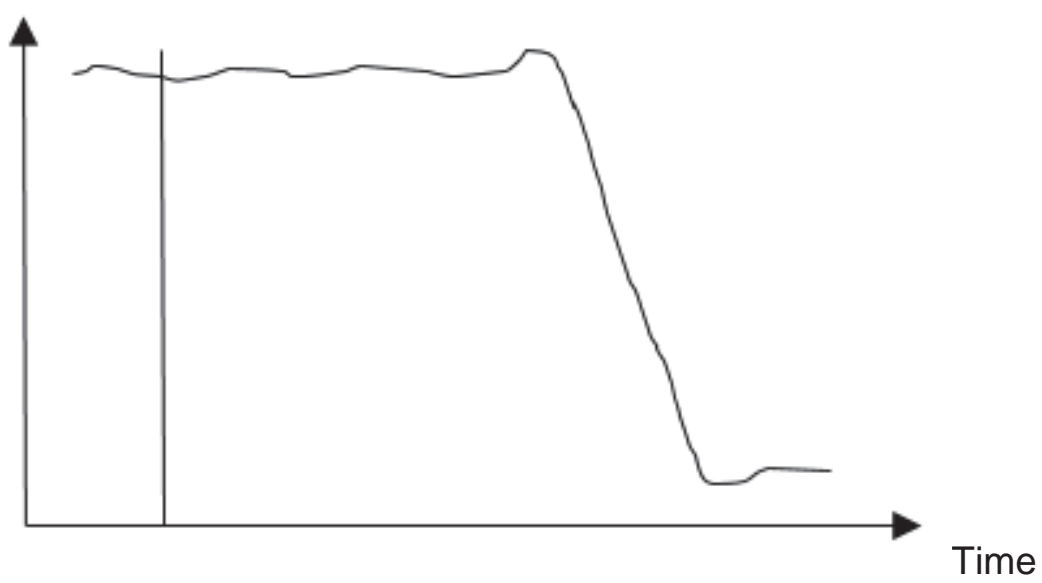

Figure 4: Di’s Vitagram

These feelings of suboptimization, not being allowed to contribute with her competence, and inconsistent, unequal treatment of employees were confirmed when the redundancy packages were to be awarded. Management did not look at the employees' collective skill set, but focused on departmental performance, although they knew that the Company would be reorganized again in the following year, this time back along subject fields and not according to market segments. She resigned as a manager and became a consultant again. At this point it was also decided that the Company would physically move to another location, which would mean a significantly longer travelling distance for her. Thus she contacted someone she knew in the headhunting industry and soon got job offers. When she stopped her unit manager was surprised, as she believed that Di was happy because she was out on a customer assignment. Di described the biggest change in the Company as going from being a company, where people cared about and stood up for each other to an organization, where people did not care, nor stood up for each other, i.e. a company where solidarity and social cohesion disappeared; among others the social environment had changed a lot. She thought that this probably was a consequence of the rapid growth and the many mergers.

\subsection{Similarities in the Consultants' Stories}

The consultants all have different and personal reasons why they chose to quit, yet there are the following similarities in their stories:

(1) All four had emotional reasons for quitting: job insecurity (Art and Curt), not being appreciated as a human being, but only be considered a billing machine (Art, Curt and Di), a feeling that management was not to be relied on (Bee and Curt).

(2) For three of the four it was one event, the lay-offs, which meant that enough was enough, but mentally they had quit before this event. ${ }^{1}$

(3) It took time from when the decision to find a new job was taken until this decision was actually implemented. Three of the four said that in this period they had withdrawn from the Company, but they felt committed to the projects they were in and to the customers they were working for.

(4) None of the four said anything about whether their direct managers had done something to persuade them to stay; admittedly, Bee and Di reported that their leaders

\footnotetext{
${ }^{1}$ Those who were laid off were either without an assignment or not key personnel in a tender at that time; being without a contract or not being key personnel in an offer affected everyone every now and then, no matter how good they were, but it varied as to how long a consultant would be without a contract. To lay employees off on the basis of such a short time frame was seen as random, deeply unfair and as very disloyal to the employees.
} 
had worked to get them onto customer assignments and thought that this was sufficient; but this was not perceived as doing something serious to change the overall situation.

(5) Two of the four were explicitly disappointed with the way their employment was terminated as no one at the Company cared about the fact that they stopped at all or expressed any regret.

(6) All appreciated their colleagues at the Company, who were mainly described as clever, willing to provide advice and help when they were asked as well as being interested in doing a good job for the customers.

(7) The four vitagram graphs all show a correlation with respect to time; all four consultants were very happy and content for a long time, with discontent emerging during the period of strong growth, the focus on shareholders and the stock exchange float and the big merger'.

(8) All four went to new employers where the content of their job was similar to the job content they had as employees of the Company; therefore it was not boring assignments or too little challenging tasks which made them quit.

(9) All four were glad that they had stopped and that they had drawn the consequences of their personal grievances; some of them also said that it was time to change job, but this was not stated as a reason why they started looking for a new job.

All four consultants explicitly referred to their loss of motivation in their tales. The concept of motivation has in the literature been related to the concept of psychological contract (Frey 2002), we therefore introduce in the following these concepts in more detail to inform our study and reflect upon our findings.

\section{Theoretical Considerations}

Rousseau (1989, 1995) who is credited with the key development of the concept of psychological contract in its current form (Guest 2004) has defined it as "An individual's belief in mutual obligations between that person and another party such as an employer" (p. 544 in Guest 2004); Morrison and Robinson (1997, p. 229) broaden this definition by asserting that "these obligations are based on perceived promises and are not necessarily recognized by agents of the organization." To emphasize that the metaphor of a contract involves at least two parties and following Morrison and Robinson (1997) who point out that although prior researchers have noted that reciprocity is a central aspect of psychological contracts, but that its role has been largely absent from research on psychological contract violation, Guest (2004, p. 545) extends the meaning of the term as follows: "The perception of both parties to the employment relationship, organization and individual, of the reciprocal promises and obligations implied in that relationship." Guest (2004) argues that the primary emphasis of the psychological contract in an employment relationship is on the individual level between the employee and employer and puts forward that such an understanding provides an opportunity to explore the processes and content of the employment relationship through a focus on more or less explicit deals; these deals are likely to be re-negotiated or modified over time, to be influenced by contextual factors, and to have a variety of consequences. Guest (2004) asserts that beyond the organizational context, the wider economic, social, and legislative context is essential for contemporary employment relations and presents an extensive number of factors that might influence the employee-employer relationship: at the individual level these are related to personal circumstances such as age, gender, education, ethnicity, tenure, income, type of work, hours worked, employment contract, work values and career anchors; at the organizational level he suggests factors such as industry sector, company size, ownership, trade union recognition, HR policies and practices, employment relations, and organizational culture. He also contends that beyond analysing the reciprocal promises, inducements, and obligations, there is a need to explore the employee's and employer's understanding of the nature of the promises and obligations and the extent to which they have 
been delivered and the circumstances under which there is positive fulfilment of the psychological contract. This includes the necessity to address the state of the psychological contract, comprising the relationship between fairness, trust, and delivery of the deal. For the latter, but not the other factors, he poses the question whether they can be conceived in either a virtuous or vicious circle to investigate their effect on the attitudes and behaviour of all parties involved in the relationship. A last crucial element of psychological contract research according to Guest (2004) concerns the outcomes of perceived contract breach and the need to know more about when they begin to matter to an extent that has significant attitudinal and behavioural consequences in the form of organizational commitment, work satisfaction, worklife balance, job security, motivation, stress, work attendance, job performance, organizational citizen behaviour and intentions to stay or quit.

\subsection{Influences Impacting on the Psychological Contract}

As a psychological contract is exposed to a number of influences, its state might change in the course of an employment and it therefore needs to be maintained. Cialdini's (2001a, b) theory of social influence and persuasion provides a starting point for understanding and identifying the influences a psychological contract is exposed to and how to uphold an acceptable psychological contract. According to Cialdini (2001a, b) people are influenced and persuaded to (accept requests to) change attitudes, beliefs and behaviours without further thinking about them through 'automatically' initiated influence processes. He presents six principles that initiate these processes and mechanisms for how they can be applied:

(1) Reciprocity: people repay in kind - give what you want to receive;

(2) Commitment and consistency: people like to be consistent and align with clear commitments - make their commitments active, public, and voluntary;

(3) Social Proof: people follow the lead of similar others - use peer power when possible;

(4) Liking: people like those who like them - uncover real similarities and offer genuine praise;

(5) Authority: people defer to experts - expose your expertise; do not assume that it is selfevident;

(6) Scarcity: people want more of what they can have less of - highlight unique benefits and exclusive information.

Reciprocity and consistency evolve over time; the other four principles can occur instantaneously, but may still affect a long-term development (Carr 2001). The principles are now explained in more detail and related to the concept of the psychological contract.

\subsection{Reciprocity}

Reciprocity is fundamental for the maintenance of a psychological contract (Carr 2001). A psychological contract involves mutual influence, interaction and negotiation between the employee and the employing organization (Carr 2001). Carr (2001) argues that the relational processes between the employee and the organization are "deep-seated; largely unconscious; intimately connected to the development of identity; and, have emotional content. Indeed, perhaps the term seduction is more appropriate than notions of mutual influence and negotiation, which are more often associated with high degrees of consciousness and rationality" (p. 429). Two key terms relating to reciprocity in a working relationship are identity and emotionality. According to Carr (2001) employees are encouraged by their employers to identify themselves with the organization's features, values and culture. Identification involves developing emotional ties to the organization, and that employees surrender some of their own identity to the organization. The ties are strengthened when employees achieve recognition and rewards through their work. Such ties create a feeling or sense of belonging, which is related to the concept of cohesion. Cohesion is about how much an employee as an individual identifies with and/ or is bound to a group. Cohesion is the social force that causes individuals to join a group, the strength of a group to define itself as a unit, 
and the strength to remain a unit (Forsyth 1999, Svedberg 2000). The difference between belonging and cohesion is that belonging is an emotional power while cohesion is a social force.

Cast and Burke (2002) discuss the relationship between identity, emotionality and self-esteem. Identity is tied to individuals' expectations of their own and of others' behaviour. When expectations are not met, negative emotions like anxiety and anger are built up. Individuals address this by adjusting their own behaviour or their expectations of others' behaviour. If the gap between expectations and their fulfilment is too big, the individuals can either remove themselves from the situation or shed their identity. When expectations are met, a confirmation of the relationship to the others is achieved and self-esteem rises. A strong selfesteem serves as an emotional reservoir if expectations turn out not to be met, and this can contribute to stability in periods of change and negative emotions. Furthermore, people with high self-esteem have greater cognitive resources that enable them to deal with unsatisfactory situations in a more effective way than people with low self-esteem. Those who get most confirmation that they do a good job will have the greatest self-esteem. Thus, they have the best basis for dealing with an emotional conflict, and it is reasonable to assume that they are the first to quit their jobs if the emotional conflict is too big. This is in line with Britt (2003) who has shown that in conflict situations those who care most about a job become those who are most demotivated and find a new job; those who stay are often the ones who do not care, a finding consistent with social exchange theory (Blau 1964, Forsyth 1999). A psychological contract contains the criteria that must be met such that employees feel that they get a sufficient return on the investment which they make in relation to the organization. If over time an employee gets less back than what they have invested (according to their own opinion), the employee will leave the relationship and the organization.

\subsection{Commitment and Consistency}

Consistency in connection with a psychological contract is the conformity between the contract's content and its actual fulfilment, i.e. whether the commitments entered into are experienced as being met. People relate to clear commitments (Cialdini 2001b). Since the commitments in a psychological contract are largely implicit and not overt, they concern the individuals' expectations about an organization. If expectations are met, an employee will fulfil the obligations they feel they have in relation to the contract, thus giving back in accordance with what has been given (see above, the reciprocity principle). If an employee gets less than expected, they will correspondingly give less than they initially felt obliged to give and if the employee gets more, they feel obliged to give more. However, inconsistency creates anxiety and anger. Employees' reaction on inconsistency, i.e. lack of behavioural integrity, is that trust and loyalty are weakened (Simons 2002). Reichheld (2001) argues that business management cannot expect employees to be loyal if they are not perceived themselves as loyal towards their customers and employees and concludes: "Outstanding loyalty is the direct result of the words and deeds - the decisions and practices - of committed top executives who have personal integrity" (p. 76). Simons' (2002) work in the hospitality industry confirms this; it shows that organizations where employees perceive that managers act consistently in relation to their obligations - they do what they said they will do - were substantially more profitable than others, and concludes that lack of trust comes at a high expense.

Kim and Mauborgne (2003) relate lack of trust and loyalty to inadequate processes in organizations. They argue that it is more important to have a fair process than to achieve a fair result, because a fair process provides emotional support i.e. it reduces negative emotions. A fair process has three characteristics: it engages, it explains and it sets clear expectations. A fair result perhaps yields what one thinks one deserves, but nothing more. According to the reciprocity principle there is thus no reason to give something extra back to the organization. Kim and Mauborgne (2003) argue that the difference between an expected and a good result corresponds exactly to the effort, which is put in voluntarily as part of a reciprocal relationship. Commitment can contribute to this in that employees remain in a relationship or an organization for some more time after negative feelings have arisen (Cast and Burke 2002). The period during which the employees have negative emotions, but wait and see, presents an 
opportunity for an organization to change behaviour by doing something in relation to the negative emotions, if it recognizes the situation, or for the employees to adjust their expectations. This provides the basis for a revised contract, where obligations and commitments are renegotiated.

\subsection{The Other Principles of Influence}

As influence is exerted through the exercise of power (Bråten 1981), it makes sense to relate the principles of social proof, liking and authority to the kinds of power which exist. Forsyth (1999) distinguishes between:

(1) Legitimate power - power that comes from a ruler's legitimate right to ask for and demand obedience;

(2) Reward power - the capacity to promise or control the allocation of a reward;

(3) Punishment power - the mandate to threaten and punish those who do not conform to a request or requirement;

(4) Reference power - influence based on identification with, attraction to or respect for those in power;

(5) Expert power - influence based on the belief that those in power have superior abilities and skills;

(6) Information power - influence based on the potential use of information resources, including rational arguments, persuasion or actual data.

Bråten (1981) has coined the notion of model power as someone's power to determine ways of understanding and talking about a phenomenon. Influence in the form of social proof occurs via 'the others' and their perceptions of whether their own psychological contract is fulfilled. If the others are satisfied and happy, this affects one's own well-being positive - and if the others feel distressed, this affected one's own well-being negatively. This influence principle can best be controlled by the exercise of power of information, based on the rule 'what people do not know, does not hurt them'. Liking relates to 'someone one identifies with and/ or looks up to,' as distinct from social proof, which relates to 'someone else', the others. When someone one knows and likes has an opinion about something, this has a stronger effect than when some unspecified others express this opinion. Liking strongly relates to reference power. Authority can be understood in two ways, as expertise (Cialdini 2001b), or as based on the mandate provided through a specific role. Experts influence through expert power and informational power, they are trusted and their advice is followed because they know best.

Designated, formal leaders are important authorities in an organization. Managers have legitimate power by virtue of their roles. They also have reward power, punishment power and information power. A manager can affect the process of upholding a psychological contract by influencing the formal contract. Terminations, layoffs, farewell packages and salary cuts are examples of elements that affect the formal contract, but which also affect the psychological contract because such measures are often associated with negative emotions (Carr 2001). Such measures will also be experienced as the exercise of punishment power. Furthermore, a leader can influence a psychological contract by making requirements concerning results, which in practice are new expectations for behaviour or by exercising reward power in the form of, for example, provision of training, bonus and/ or salary increases. In addition, managers have the opportunity to practice various forms of information power such as control of the agenda (Bachrach and Baratz 1962) by determining what is informed and communicated about or model power (Bråten 1981) by creating strategies and structures for interaction. The exercise of power by a manager can thus have effects which lead an employee to believe that the organization does not appear to be consistent and thus does not fulfil its part of the psychological contract. It is not the exercise of leadership itself that affects whether the psychological contract is considered as fulfilled or not, but the perception of the exercised leadership. 
Finally, scarcity can affect the psychological contract as it affects the scope of action when an employee is experiencing emotional conflicts. If many jobs are on the market, it is easier or more tempting to try to find a new job than if there are few jobs. As discussed with regard to reciprocity, it is not certain that everyone will react alike to scarcity. Consultants who do not get their identity confirmed through their work have lower self-esteem than those who get confirmation that they do a good job. Those with lower self-esteem may not seek other jobs in times of job scarcity, even though they might like to do so. Thus, scarcity can be an influence, which does not affect those with high self-esteem, but which leads those with less self-esteem to stay.

\subsection{The Content and State of the Psychological Contract}

Morrison and Robinson (1997) as stated earlier emphasise the significance of reciprocity for the content and state of a psychological contract and put forward that "The psychological contract held by an employee consists of beliefs about the reciprocal obligations between that employee and his or her organization." (p. 226) The content and state of the psychological contract is related to finding meaning and being satisfied in one's job and with one's work (Morse 2003), to be allowed to do one's best (Britt 2003), to feel enough certainty to grow with a task, and enough uncertainty that it becomes necessary to grow with a task (Moxnes 2000). It is also related to emotional support and belonging (Forsyth 1999), to engagement, to clear expectations and to explanations why decisions are taken (Kim and Mauborgne 2003). People engage in their work for the challenge and the enjoyment of it, the work itself is motivating; Amabile (1998) calls this intrinsic motivation. As such intrinsic motivation is an important part of a psychological contract. In refining the general relationship between the psychological contract and motivation, Frey (2002) supports this by stating that a psychological contract includes a reciprocal appreciation of intrinsic motivation. De Lange et al. (2011) have examined the direct relationship between psychological contract and intrinsic motivation in a quantitative study and found that relational contract violation predicts lower work motivation. Amabile (1998) has earlier identified six categories of management practice, which when utilized, promote intrinsic motivation, and when neglected inhibit it. Each category also includes some pitfalls and management practices which inhibit intrinsic motivation. The categories and pitfalls which contribute to the content and state of a psychological contract, according to Amabile (1998), are:

(1) Challenge: is about assigning the right task to the right person, so the employees have something to strive for; if a task is too little challenging it becomes boring, but if it is too challenging it can create fear of losing control; the pitfall here is to give a task to someone, who incidentally has no actual assignment.

(2) Freedom: is about setting unambiguous and clear goals, but to give the employees influence concerning the way to reach the goal; it is important that the goals are stable over a relevant time period; pitfalls here area) to change goals too often or not to define the goals properly, and b) to provide the illusion of free choice in a process that is predetermined.

(3) Resources: is about allocating time and money; insufficient resources give no space for challenges, or make it impossible to get a task done; too many resources will also affect the results negatively; the pitfall here is to miscalculate the actual need for time and money.

(4) Work-Group Features: is about putting together a working group that consists of people with sufficiently diverse backgrounds and of people, who can form a group whose members are mutually supportive; the pitfall here is to put together groups of employees, who are too similar, their members will easily cooperate, but they will hardly be able to create something new.

(5) Supervisory Encouragement: is about the feeling to mean something and about providing the feeling that an employee does matter to the organization or to an 
important group of people; pitfalls here are a) not to show attention and b) to meet employees' newideas with too much criticism.

(6) Organizational Support: is about the procedures and mechanisms to promote and reward creative solutions, particularly by facilitating information sharing and collaboration; pitfalls here are a) to reward in the form of money that gives the employees the feeling of being bribed and b) to install policies and reward systems, which inhibit information sharing and collaboration.

\subsection{A Cyclic Process Model of the Maintenance or Neglect of the Psychological Contract}

The empirical findings of our study uncover elements that can be consolidated into a cyclic process model of the maintenance or neglect of a psychological contract.

Employees enter a psychological contract with their employing organization when they start an employment relationship (Rousseau 1995, Morrison and Robinson 1997, Carr 2001, Guest 2004). The data documents the relationship between the psychological contract and intrinsic motivation (Amabile 1998, Frey 2002) and the literature confirms that maintaining and upholding intrinsic motivation is a vital part of the content of the psychological contract (Frey 2002).

The four interviewed consultants had expectations concerning the Company's behaviour, in particular in regard to mutual obligations and commitments. The literature on social influences, which emphasizes the role of reciprocity, commitment and consistency and associated expectations for a psychological contract and its fulfilment, reinforces this finding (Cialdini 2001a, 2001b, Carr 2001). Cialdini (2001a, b) also puts forward that an employee's perception of whether the organization acts consistent with the psychological contract is influenced by the principles of social proof and liking, and that revisions and adjustments of the psychological contract can be affected by the principle of scarcity, especially if emotional conflicts arise.

The consultants explained that they compare their expectations with their experiences and revealed positive and negative feelings such as confirmation of their status and their relation, trust and loyalty to the organization, but also their diminished trust, abated loyalty, anger and anxiety as a consequence of that comparison. Authors such as Cast and Burke (2002) and Kim and Mauborgne (2003) back up these experiences and the described expectation gaps as they relate issues of identity and emotionality, but also of self-esteem, to trust and loyalty.

As an effect of the expectation gaps and the accompanying feelings and emotions the consultants also expressed how their motivation, which the literature qualifies as intrinsic motivation (Amabile 1998, Frey 2002) in form of their sensations of exclusion, belonging, closeness and distance to the organization, either remained stable or increased or decreased. This has been discussed in the literature by Forsyth (1999), Svedberg (2000), Carr (2001) as well as Cast and Burke (2002) who refer to the concepts of sense of belonging and cohesion. The current status, including any change, of their intrinsic motivation led the consultants to recurrently assess their actual relation to the Company that is to revisit their psychological contract and to either maintain or adjust its content by altering their expectations, but also their commitments and obligations.

Subsequently these expectations were regularly compared with the organizational behaviour shown by the Company and the consultants mentioned a number of managerial practices and the lack hereof which can be linked to the practices of challenge, freedom, resources, working group features, supervisory encouragement, and organizational support as identified by Amabile (1998). These practices which are also related to theaforementioned social influences of reciprocity, commitment and consistency, but also to management's authority (Cialdini 2001a, b, Carr 2001) and their exercise of power (Bråten 1981, Forsyth 1999) impacted their ensuing experiences. 
In the course of time the consultants went through several of these cycles of managerial practices impacting social influences and creating expectations and expectation gaps with their positive and negative effects on intrinsic motivation and ultimately their psychological contract. Their commitments followed an immanent need to give more back when they received more than expected (Cialdini 2001a, b) and less when they received less than expected (Kim and Mauborgne 2003).

The consultants, who initially all were content, i.e. had a strong sense of belonging to the Company, all had an emotional surplus called an emotional reservoir by Cast and Burke (2002). Even in bad times and after a bad cycle they did not lose all their intrinsic motivation nor did they terminate their psychological contract and employment relationship at once, but hoped for improvements, waited and observed. These were attempts to re-establish their psychological contracts to become again consistent with the commitments, which they had made through their original contracts.

They experienced both good cycles and bad cycles. A good cycle in the process of maintaining the psychological contract was characterized by a situation where their expectations were more than fulfilled, they got more back from the organization than what they expected and as a consequence their sense of belonging to the Company either kept level or was strengthened. The consultants adjusted their contracts and altered their commitments and obligations to the Company as well as their expectations and in line with the principle of reciprocity responded with an aspiration to give even more back to the organization than what they were obliged to.

The consultants however more often got less than expected, their sense of belonging to the Company was weakened and they decided to give less back than what they initially felt obliged to - these were bad cycles in the process of maintaining the psychological contract. Thus, when no intrinsic motivation remained due to repetitive non-fulfilment of expectations and negative evaluations, they terminated both the psychological and their formal contract and left the Company.

This continuous process which we derived from the empirical data and which is substantiated by different segments of the literature integrated here into a coherent whole can be synthesized and depicted in a cyclic process model of the maintenance or neglect of the psychological contract (see figure 1). 


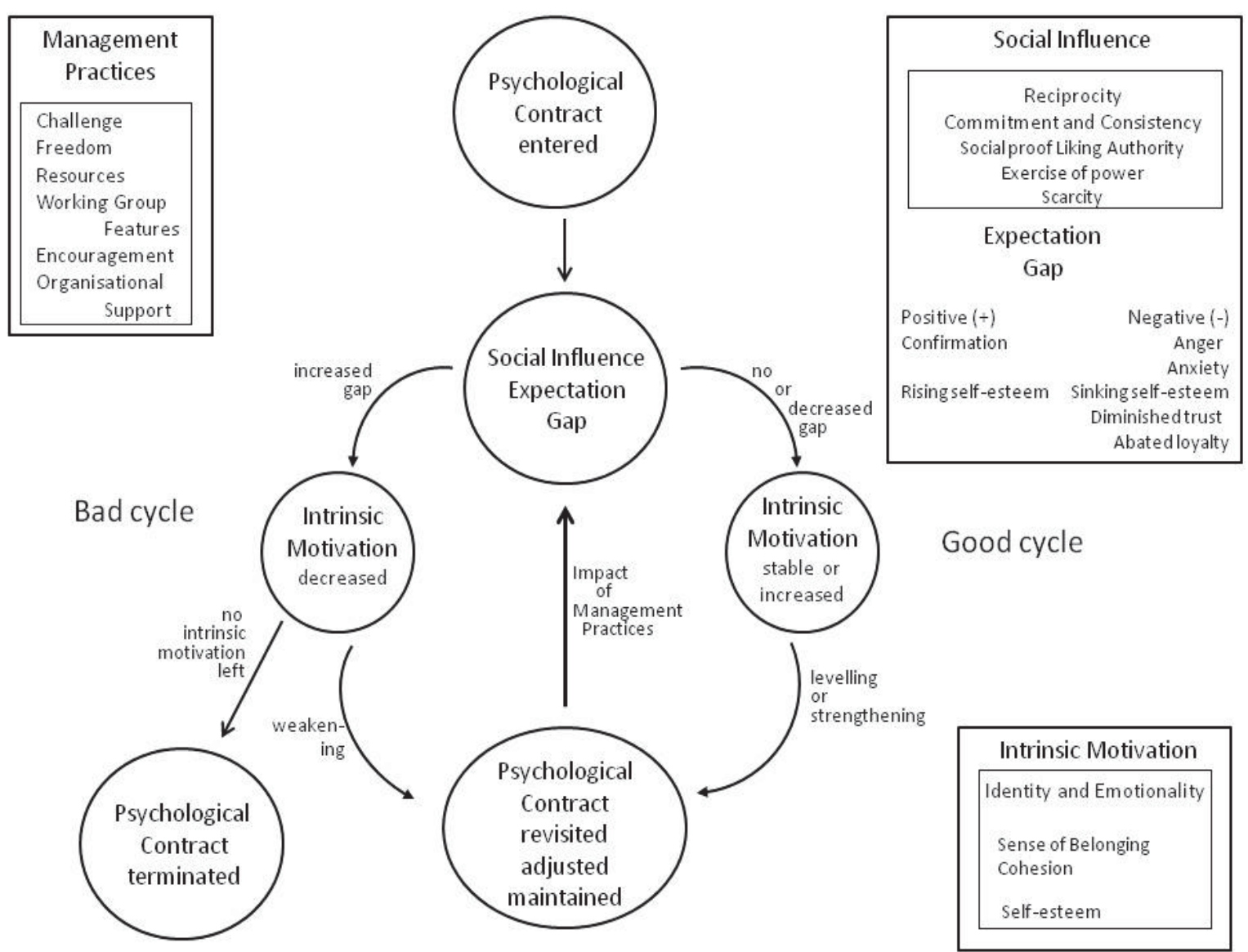

Figure 1: A process model for the maintenance or neglect of the psychological contract

The model follows the logic of a process theory, which means that causation consists of necessary conditions in a sequence (Markus and Robey 1988) where the absence of one such required condition will impede the outcome from occurring.

\section{The Tales and the Psychological Contract: An Analysis}

We can now revisit the consultants' tales and relate them more closely to the cyclic process model for the maintenance or neglect of the psychological contract. First, we focus on the relation between the consultants' actual expectation gap, the social influences, their intrinsic motivation and their psychological contracts. Secondly, we concentrate on the relationship between the content and state of the psychological contract and the identified management practices. Finally, we relate the tales to bad cycles captured in the model which result in the total loss of intrinsic motivation, the end of the psychological contract maintenance process, as well as the psychological contract and the consultants' voluntary job termination.

\subsection{The Tales, Expectations, Influences, Intrinsic Motivation and the Psychological Contract}

From the consultants' tales we recall that:

- $\quad$ Art first experienced a disappointment with a poorly composed team of consultants, scaled his expectations down and withdrew mentally. When the same letdown returned, he decided to stop. This decision was however not implemented before the lay-off came, then he handed in the notice without having a new job to go to.

- $\quad$ Bee had a downturn at the beginning of her career in the Company. Then her motivation went up; her expectations were met, and they actually rose. When the 
Company focused too much on short-term profits and too little on long-term survival, her motivation went down, but went up again when the organization focused on something she was interested in and finally straight down when the Company nevertheless didn't focus on that area. She left when she was offered a new job.

- $\quad$ Curt had many setbacks over a long period. His expectations of the Company were met over time and towards the end of his employment he felt that the Company management was stingy and uninterested in its employees. His attitude became 'why give something to the Company when the Company has nothing to give?' The economic insecurity caused by the variable pay model resulted in his final decision to go, although he had had a small resurrection when he thought that the Company would not introduce variable pay after all.

- $\quad$ Di had a number of setbacks over a very short period. In her role as a manager she was disappointed about the lack of cooperation, recognition and mandate for her work which did not meet her expectations. She also disagreed with the way the redundancy packages were determined, but persevered as a consultant. However her sense of belonging to a Company which she described as careless, unfair and showing a lack of solidary had weakened too much, thus when a proposition for a new job came, she accepted the offer and left the Company.

The consultants' tales exhibit some common features in terms of maintaining their psychological contract:

(1) There as a relation between identity and emotionality, specifically, negative emotions, and sense of belonging.

All four consultants stated emotional reasons for terminating their jobs. Negative emotions, such as resentment, disappointment, mistrust, but also angst led to a decrease in their sense of belonging to the Company, but the loyalty to the customers did not drop, neither in the Company in general nor by the consultants in particular. They felt committed to their customers and they also perceived that their colleagues were striving to do a good job for the customers. The consultants' self-esteem did not fall either; none of the four consultants had experienced problems in relation to being without a contract for a long time period and had survived several rounds of cutbacks and layoffs. In a consulting firm many contracts give status - salary and bonus - as contracts mean billed hours. Contracts also mean more contracts because it is easier to get a new assignment when a consultant has been on assignments before; here the customers are affected by social proof. To put it forcefully: contracts and assignments are a basis for expert power, reference power and information power. All of the four consultants went on to newjobs with similar content to what they had in their positions at the Company.

(2) Social proof, liking and scarcity had an impact on perceptions of consistency, but were not decisive in relation to making the decision to leave their job.

None of the four consultants ceased their employment because someone in particular had also done so; the principles of social proof and liking did not influence them in these respects, although both Bee and Curt stated that when many other employees left and others started, something happened to the identity of the employees and their sense of belonging in general. Yet this was not their major reason to terminate their employment contracts. The consultants' self-esteem with regard to their assignments and contracts was large enough that a scarcity of jobs did not prevent them from quitting either. However they did the only rational thing from their perspective, they moved from a business which they no longer wished to be part of and continued with what they were good at somewhere else.

(3) The consultants went through several, mostly negative cycles in the model. 
All consultants had several rounds of negative cycles. Each round in a negative cycle affected the consultants' commitment to their psychological contract as they became more and more dissatisfied. As their vitagrams indicate they probably expected less from the organization, but they did not quit. In this way they gave the Company a chance to change its behaviour. The vitagrams also show that it is possible to reverse a negative trend. This is perhaps most evident in Bee's case, where the curve went from way down up to high again, but also in Curt's case where a small upwards turn occurred. The reversal of the negative trends happened when the consultants perceived that the Company changed its behaviour, but the taken measures were not sufficient.

\subsection{The Tales, the Management Practices and the Consultants' Psychological Contracts}

The consultants' tales are strongly related to management practices (Amabile 1998), which impacted the state of their psychological contracts and their intrinsic motivation as part of the content of these contracts. An analysis of these management practices contributes to an explanation of why the consultants left their jobs.

The reason why Art resigned was a combination of little challenge, wrong work-group features, lack of organizational support, and too much freedom: he did not get the right job assignments with regard to his expertise, he was assigned to project groups which were composed of people with the wrong skills, and he felt that no one in management did anything with these issues. This happened twice. Art also thought that the organization's objectives and goals were too vague and very unclear to the employees.

The first time Bee resigned can be attributed to a lack of supervisor encouragement from management and a lack of resources as her tasks did not fit with the time that was available. However she stayed because she got a new challenge. When she finally resigned, the reason was that management did change goals again and did not hold on to those goals she worked towards long enough that reaching any results was possible, i.e. her reasons were a combination of lack of freedom and resources.

Curt finally quit because of a lack of supervisor encouragement from management; heprovided several examples of that it did not matter when the consultants put in an extra effort; it was just not seen. In addition, there was a lack of organizational support, where the reward system for managers led to many management activities that were related to their goals, not the organization's goals. Curt was the most outspoken with regard to the fact that his intrinsic motivation disappeared, which he related to his well-being, enthusiasm, commitment, motivation, and loyalty and considered absolutely necessary for a good work place for oneself and others.

Di felt a lack of supervisory encouragement and lack of organizational support; the ultimate reasons why she stopped were primarily related to the characteristics of her work group. The management group did not have the qualities of a good group where "First, the members must share excitement over the team's goal. Second, members must display a willingness to help their teammates through difficult periods and setbacks. And third, every member must recognize the unique knowledge and perspective that other members bring to the table." (Amabile 1998, p. 83)

Some of the similarities in the stories are also related to the management practices. One of the managers at the Company believed that it was enough to get consultants out into customer projects to get them to stay, but that did not help. We can speculate that these assignments were not challenging enough to increase the consultants' intrinsic motivation. Based on the considerations that the sense of belonging to the Company was already weakened, it is reasonable to assume that more supervisor encouragement from management, i.e. interest and commitment from the managers' side would have been necessary to convince the consultants to stay. 
Three consultants said that the lay-offs, which were a dramatic change in some colleagues' formal contracts, led them to lose all trust in management and as such were key events with regard to deciding not to go more cycles in the process of maintaining their psychological contracts. The lay-offs were perceived as a fundamental lack of managerial supervisor encouragement and organizational support. The employment terminations, where employees were 'thrown out' of the organization without so much as 'thank you and good luck' admittedly did not explicitly influence the consultants' intrinsic motivation, but confirmed that it had been the right decision to leave the organization.

\begin{tabular}{|l|c|c|c|c|}
\hline \multicolumn{1}{|c|}{ Consultant } & & & & \\
Managerial Practice & Art & Bee & Curt & Di \\
\hline Challenge & $\sqrt{ }$ & & & \\
\hline Freedom & $\sqrt{ }$ & $\sqrt{ }$ & & \\
\hline Resources & & $\sqrt{ }$ & & \\
\hline Working Group Features & $\sqrt{ }$ & & & $\sqrt{ }$ \\
\hline Supervisor Encouragement & & $\sqrt{ }$ & $\sqrt{ }$ & $\sqrt{ }$ \\
\hline Organisational Support & $\sqrt{ }$ & & $\sqrt{ }$ & $\sqrt{ }$ \\
\hline
\end{tabular}

Table 1: Managerial practices neglecting the psychological contract

In summary, all the consultants stated management practices, which inhibited intrinsic motivation as their reasons for terminating their employment (see table 1).

\subsection{The Tales, Bad Cycles and Termination of the Psychological Contract}

The consultants all experienced mostly negative cycles of the maintenance of their contracts and ultimately left the Company because their psychological contracts were all poorly maintained or more precisely neglected as they went through several cycles. The cycles were bad because management did not deploy management practices that provide the conditions to uphold intrinsic motivation. We have described the gap between all employees' expectations and their experiences which resulted in negative emotions including reduced trust and loyalty and led to a situation where the consultants resigned mentally long before they physically left. As nothing was done to increase their intrinsic motivation to work for the Company they left, but eventually continued in quite similar jobs at different employers.

The process started with a psychological contract being entered into between each of the four consultants and the Company. A bad cycle then commenced when the Company did not meet the employees' expectations concerning social influences, in particular reciprocity and commitment and consistency, and less so authority including exercise of power, social proof and liking. Scarcity of jobs on the market did not play any role. This expectation gap with the associated negative emotions resulted in the consultants' intrinsic motivation, in particular their sense of belonging to the Company, being weakened. The weakened relationship with the Company subsequently led to the consultants' revision of their psychological contracts with the outcome that their faith in and loyalty to the Company compared to the trust and devotion, which they initially had, decreased. Their loyalty to customers however was sustained.

Both the original and the revised psychological contract were exposed to management practices such as a shortage of challenges, too much freedom, dearth of resources, paucity of supervisory encouragement, and lack of organizational support which continuously impacted the consultants' experiences of social influences and created a widened expectation gap which lead to further adjustments of the psychological contract with regard to expectations.

The consultants went through several bad cycles with some of them experiencing small improvements in between cycles, and all of them waiting for change for the better until at one point there was no intrinsic motivation left and they terminated their employment. The eventual lack of organizational support in form of the layoffs which were perceived as unfair, and in one case the variable pay model which was considered as unjust, provided the ultimate 
cause for the loss of motivation and the termination of the psychological and the formal contract.

\section{Discussion}

In this study we have argued that employees in an IT consulting firm terminated their employment with the organisation because their psychological contracts were poorly maintained throughout several cycles. The poor maintenance consisted mainly of management practices, which destroyed the consultants' intrinsic motivation. By relating and combining the empirical findings of our study with insights concerning the psychological contract (Rousseau 1995, Morrison and Robinson 1997, Carr 2001, Guest 2004), the principles of social influence (Cialdini 2001a, b), theories of power (Forsyth 1999, Bråten 1981) and of the relation between self-esteem, identity and emotionality (Cast and Burke 2002) with the principles of social influence (Cialdini 2001a, b) and categories of management practices(Amabiles 1998), which promote intrinsic motivation, we established a general process model of how psychological contracts are maintained or neglected.

We conceptualize and demonstrate the maintenance or neglect of the psychological contract as a continuous, cyclic process, where the cycles can be 'good' or 'bad', as seen from an employee's perspective. The tales of the four consultants can be understood in terms of the model. The primary reasons why they were less satisfied with working in the case organization could be related to the pitfalls of management practices (Amanile 1998), which damage intrinsic motivation.

Previous research has dealt with the concept of psychological contracts differently. Morrison and Robinson (1997) present a linear causal logic model that focuses on the development of violation of the psychological contract. It outlines the sense-making processes preceding an employee's experience of a contract violation based on two key factors: reneging, organizational agents knowingly breaking a promise to an employee, and incongruence of the employee's and agents' understandings of a promise. A perceived unmet promise creates a discrepancy between an employee's understanding of what was promised and her perception of what she actually has received. The perception of this discrepancy triggers a comparison process, whereby the employee considers how well each of the parties has upheld its respective promises, but the model pays no attention to the consequences, nor does it address possible feedback loops or cycles.

Out of his extensivelist of identified factors (see the 'Theoretical Considerations' section) Guest (2004) develops a factor-based, uni-directional causal framework for applying the psychological contract to the employment relationship. He takes contextual, background, policy and practice factors as well as characteristics of the psychological contract and its actual state into account and deduces attitudinal and behavioural consequences. His model considers the intention to stay or quit as a possible outcome, but does not go further.

Based on the insight that perceptions of fairness evolve over time J ones and Skarlicki (2013) present a dynamic model of organizational justice in which they describe the processes through which perceptions of fairness change. The model describes a cyclical process whereby individuals' cognitive processing and judgments about the fairness of an event are guided by their perceptions about the organizational entity involved. It does however not focus on psychological contract as such and does not deal with the consequences of unchanged and changed perceptions. As with the other presented models their model has not been empirically validated.

Our work is based on the existing definitions of the psychological contract and like Morrison and Robinson (1997) and Guest (2004) we emphasize the crucial role of reciprocity in a psychological contract. As our main contribution the model we present builds on this prior work and extends it with a focus on maintenance, good and bad, of the psychological contract in a cyclic process and we derive and thus validate our model empirically. 
Until now we have looked at the process of change from engaged employee to volunteer job seeker from the individual employee's perspective. But the individual consultants are employed and part of a business organization, an IT consulting firm. Thus in the following, we will look at the consultants' stories in a different context - from the organization's perspective and discuss what it means for the organization that employees leave, and how it could happen that the Company was no longer able to maintain the consultants' intrinsic motivation.

Does it matter for the organization that experienced employees leave in frustration? For those who have left, it is certainly a relief to have made the decision and for them it is positive that they did something with a work situation which they did not like. For the organization this may have various consequences. Of course when someone leaves, it means new opportunities for those who stay. But like in the Company, it is often the best and most engaged (Britt 2003) who leave first. The best people leaving reduces the sense of belonging and loyalty of those who stay as one of their colleagues, someone like themselves, did not think that the organization was a good enough place to work and social support and expertise disappear with those who used to provide it. For the organization the loss of experienced consultants may lead to the loss of contracts and work assignments, and thus loss of revenue, especially in times of great competition for these contracts. In itself it is neither good nor bad that someone ceases their employment. But if many employees leave because their intrinsic motivation is destroyed due to poor management practice, this means that the employees have found individual solutions for a problem, which actually is located at the organizational level (Schein 1999).

How could this happen at the Company and what has led to the situation where the Company's managers who were good at motivating their employees until the late 1990s were no longer able to do so? During this period the Company experienced rapid growth, first organic and then by mergers. Shortly after the mergers were completed, the IT consulting market hit rock bottom and this resulted in several rounds of staff reductions in the Company. The consultants' statements about the development of the Company's organizational culture documents how they felt about what happened in the Company. Bee was disappointed that no one took responsibility for the 'price' the organization had to pay for the growth, that no one handled the problems that mergers bring with them in the form of different organizational cultures, different understanding of goals and different practices. Curt put forward that the Company changed from being a business with great openness and participation, where individual differences were seen as a strength, and which was also managed according to individual needs, to an organization that was completely closed, an organization without co-determination, where the 'individuals have vanished', and where governance was addressed by purely economic principles. Those who managed and rewarded, saw only numbers, not people. Finally, Di said that the biggest difference was that people did not care anymore and would not engage and help each other out anymore. The descriptions of the cultural changes correspond to the mechanisms to avoid organizational anxiety as described by Moxnes (2000):

(1) Removing emotions: by keeping distance and not getting involved as described by Curt and Di;

(2) Removing the problem: by not taking problems in connection with change serious supported by Bee's statement about management's unwillingness to pay the price for growth;

(3) Removing people: by reducing people to objects, see Curt's statements;

(4) Institutionalising silence: by either not talking about something or talking about something completely different - supported again by Curt's observations;

(5) Removing responsibility: by blaming the consultants for the Company's poor results because according to management the consultants did not sell enough; none of the consultants had mentioned this issue explicitly in the interviews, but that management had failed in this respect was an opinion, which was implicitly shared by many employees and observed during the data collection. 
According to Mao Tsetung (1937) the fact that the number of employees is changing rapidly over a short time brings with it anxiety and imbalance, which in turn enforces major changes, although these are not intended. Major changes lead to organizational anxiety because basic structures such as goals and rules no longer are perceived in a shared way, roles become unclear and informal social structures break up (Moxnes 2000). The organization falls into many different groups, which hold dissimilar basic assumptions and disintegrates as power struggles develop when new structures are established to deal with organizational anxiety (Svedberg 2000).

When organizational anxiety has grown to an extent that avert mechanisms occur, the organization develops characteristics which are inconsistent with the management processes that promote intrinsic motivation. The major changes in a short period of time apparently resulted in organizational anxiety in the Company. This anxiety was met with averting mechanisms that made it difficult to exercise management practices that promote intrinsic motivation with the consequences described above.

\section{Conclusion}

The presented model of the maintenance or neglect of the psychological contract as a continuous, cyclic process presents a fresh perspective on a phenomenon which has long been studied in the behavioural and organizational sciences and which is important for IS research and practice as well. Derived from empirical data and substantiated through literature, the model has only been validated and specified based on a limited number of revelatory case studies in a single case organization. We acknowledge that this approach initially only generates a local empirical theory, but it contributes to the existing body of knowledge by providing a detailed account of empirical findings. The model exhibits in its current form an instance of theorizing through idealization, which needs to be further validated through further cases. Although we were not interested in generalization as such, with its focus on the concept of psychological contract the model and its theoretical background are still useful and help explain IT consultants' behaviour of voluntarily terminating their employment contracts beyond the crisis situation, which the IT industry experienced some years ago and which motivated this research originally. It should assist managers also in a more general context in avoiding practices which might lead to their employees' loss of intrinsic motivation and as a consequence to the loss of valuable employees for their organization.

\section{References}

Amabile, T. 1998. “How to kill creativity,” Harvard Business Review (76:5), pp. 76-87.

Argyris, C. 1960. Understanding Organizational Behavior. Homewood, IL, USA: Dorsey Press.

Armstrong, D., Lilford, R., Ogden J ., and Wessely S. 2007. "Health-related quality of life and the transformation of symptoms," Sociology of Health and Illness (29:4),pp.570-583.

Asselin, M. E. 2003. "Insider research: Issues to consider when doing qualitative research in your own Setting," J ournal for Nurses in Staff Development (19:2), pp.99-103.

Bachrach, P., and Baratz. M. 1962. "Two Faces of Power," The American Political Science Review (56:4), pp.947-952.

Barney, J . 1996. Gaining and Sustaining Competitive Advantage, Reading: Addison-Wesley.

Blau, P. 1964. Exchange and power in social life. New York, NY, USA: Wiley.

Britt, T. W. 2003. “Black Hawk Down at Work,” Harvard Business Review (81:1), pp. 16-17.

Bråten, S. 1981. "Quality of Interaction and Participation - On Model Power in Industrial Democracy and Computer Networks," in Applied Systems and Cybernetics, G. E. Lasker (ed.), vol. I, pp. 191-200. 
Carr, A. 2001. “Understanding emotion and emotionality in a process of change," J ournal of Organizational Change Management (14:5), pp. 421-434.

Cast, A., and Burke, P. 2002. “A Theory of Self-Esteem," Social Forces (80:3), pp.1041-1068.

Cialdini, R. 2001a. Influence, Science and Practice, 4th ed., Boston: Allyn and Bacon.

Cialdini, R. 2001b. "Harnessing the Science of Persuasion," Harvard Business Review (79:9), pp. 72-79.

Creswell, J. W. 2003. Research design - Qualitative, Quantitative and Mixed Methods Approaches, Thousand Oak, CA: Sage Publications.

De Lange, A. H., Bal, P. M., Van der Heijden, B. I. J . M., de J ong, N., Schaufeli, W. B. 2011. "When I'm 64: Psychological contract breach, work motivation and the moderating roles of future time perspective and regulatory focus", Work \& Stress: An International J ournal of Work, Health \& Organisations (25:4), pp. 338-354.

Forsyth, D. 1999. Group Dynamics, 3rd Edition, Belmont: Wadsworth Publishing Company.

Frey, B. S. 2002. Inspiring Economics: Human Motivation in Political Economy. Cheltenham, UK : Edward Elgar Publishing.

Gabriel, Y. 2000. Storytelling in Organizations, Oxford, UK: Oxford University Press.

Gerring, J. 2007. Case Study Research: Principles and Practices, Cambridge: Cambridge University Press.

Ghazawneh, A., and Henfridsson, O. 2013. "Balancing Platform Control And External Contribution In Third-Party Development: The Boundary Resources Model," Information Systems J ournal (23:2), pp.173-192.

Glaser, B. G. 1992. Basis of Grounded Theory Analysis: Emergence vs Forcing, Sociology Press, Mill Valley, CA, USA: Sociology Press.

Glaser, B.G., and Strauss, A.L.1967. The Discovery of Grounded Theory - Strategies for Qualitative Research. New York, USA: Aldine De Gruyter.

Guest, D. E. 2004. "The Psychology of the Employment Relationship: An Analysis Based on the Psychological Contract," Applied Psychology: An International Review (53:4), pp. 541- 555.

Hansen, B., and Kautz, K. 2005. "Grounded Theory Applied - Studying Information Systems Development Methodologies in Practice," in Proceedings of the 38th Hawaii International Conference on System Sciences, Big Island, USA, J anuary 3-6, 2005.

Hughes, J., and J ones, S. 2003. "Reflections on the use of grounded theory in interpretive information systems research," in Proceedings of the ECIS 2003 Conference, Naples, Italy.

J ones, D. A., and Skarlicki, D. P. 2013. "How perceptions of fairness can change: A dynamic model of organizational justice," Organizational Psychology Review (3:2), pp. 138- 160.

Kanuha, V. K. 2000. “Being” native versus "going native”: Conducting social work research as an Insider," Social Work (45:5), pp. 439-447.

Kendall J . E., and Kendall K.E. 2012. "Storytelling as a Qualitative Method for IS Research: Heralding the Heroic and Echoing the Mythic," Australasian J ournal of Information Systems (17:2), pp. 161-187.

Kim, W. C., and Mauborgne, R. 2003. "Fair Process: Managing in the Knowledge Economy", Harvard Business Review (81:1), pp.127-136.

Kjærgaard, A., and, Kautz, K. 2008. "A process model of establishing knowledgemanagement: Insights from a longitudinal field study," Omega - The International J ournal of Management Science (36:2), pp. 282-297. 
Langley, A. 1999. "Strategies for Theorizing from Process Data," Academy of Management Review (24), pp. 691-710.

Locke, K. 2001. Grounded Theory in Management Research, Sage Publications, London, UK: Sage Publications.

Lopreato, J., and Alston, L. 1970. "Ideal Types and the Idealization Strategy," American Sociological Review (35), pp. 88-96.

Markus, M.L., and Robey, D. 1988. "Information Technology and Organizational Change: Causal Structure in Theory and Research,” Management Science (34), pp. 583-598.

Morrison, E.W., and Robinson, S.L. 1997. 'When employees feel betrayed: A model of how contract violation develops," Academy of Management Review (22), pp. 226- 256.

Morse, G. 2003. “Why We Misread Motives,” Harvard Business Review (81:1), p. 18.

Moxnes, P. 2000. Positive anxiety of the individual, a group and organization (in Norwegian), 3rd ed., Oslo, Norway: Paul Moxnes Publishing.

Reichheld, F. 2001. “Lead for Loyalty,” Harvard Business Review (79:8), pp. 76-84.

Rousseau, D. M. 1989. "Psychological and implied contracts in organizations," Employee Responsibilities and Rights J ournal (2), pp. 121-139.

Rousseau, D. M. 1995. Psychological contracts in organizations. Thousand Oaks, CA, USA: Sage.

Sabherwal, R.1999. "The Role of Trust in Outsourced IS Development Projects," Communications of the ACM (42:2), pp. 80-86.

Schein, E. 1970. Organizational Psychology, 2nd Edition, Englewood Cliffs, NJ, USA: Prentice-Hall.

Schein, E. 1999. Process Consultation Revisited. Building the helping relationship, Reading, MA, USA: Addison-Wesley.

Simons, T. 2002. "The High Cost of Lost Trust," Harvard Business Review (80:9), pp.2-3.

Strauss, A., and Corbin, J. 1998. Basics of Qualitative Research. London, UK: Sage Publication.

Svedberg, L. 2000. Group psychology - About groups, organizations and leadership (in Swedish), 2nd edition, Lund, Sweden: Studentlitteratur.

Tsetung, Mao 1937. “On contradiction," in Tsetung, Mao (1978): Selected works (in Norwegian), vol. 1, pp. 311-348, Oslo, Norway: October Publishers.

Walsham, G., "Interpretive case studies in is research: nature and method", European J ournal of Information Systems (4:2), pp. 74-81, 1995.

Weber, M. 1949. The Methodology of the Social Sciences. Glencoe, IL, USA: Free Press.

Yin, R.K. 2009. Case Study Research: Design and Methods, 4th ed., Thousand Oaks, CA, USA: Sage Publications.

Copyright: (C) 2015 Kautz \& Bjerknes. This is an open-access article distributed under the terms of the Creative Commons Attribution-NonCommercial 3.0 Australia License, which permits non-commercial use, distribution, and reproduction in any medium, provided the original author and AJ IS are credited. 


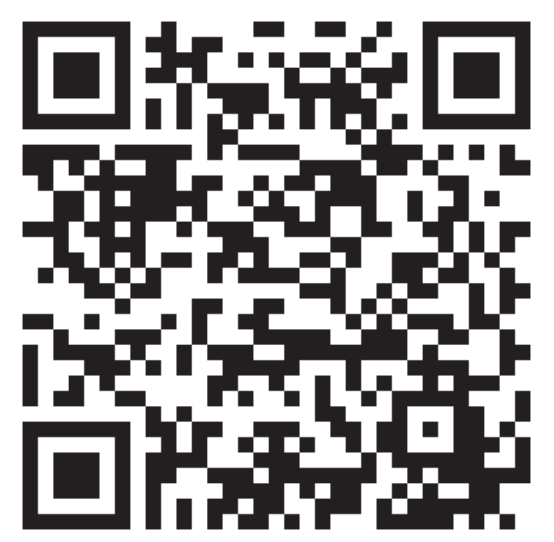

